\title{
Increasing the Reactivity of Diborenes: Derivatization of NHC- Supported Dithienyldiborenes with Electron-Donor Groups
}

\author{
Dominic Auerhammer, ${ }^{a, b}$ Merle Arrowsmith, ${ }^{a, b}$ Philipp Bissinger, ${ }^{a, b}$ Holger Braunschweig, ${ }^{a, b, *}$ Theresa \\ Dellermann, ${ }^{a, b}$ Thomas Kupfer, ${ }^{a, b}$ Carsten Lenczyk, ${ }^{a, b}$ Dipak K. Roy, ${ }^{a, b}$ Marius Schäfer $^{a, b}$ and Christoph \\ Schneider ${ }^{\mathrm{a}, \mathrm{b}}$
}

\begin{abstract}
A series of NHC-supported 1,2-dithienyldiborenes was synthesized from the corresponding (dihalo)thienylborane NHC precursors. NMR and UV-vis spectroscopic data, as well as X-ray crystallographic analyses, were used to assess the electronic and steric influences on the $\mathrm{B}=\mathrm{B}$ double bond of various $\mathrm{NHCs}$ and electron-donating substituents on the thienyl ligands. Crystallographic data showed that the degree of coplanarity of the diborene core and thienyl groups is highly dependent on the sterics of the substituents. Furthermore, any increase in the electrondonating ability of the substituents resulted in the destabilization of the HOMO and greater instability of the resulting diborenes.
\end{abstract}

\section{Introduction}

Unlike carbon-carbon double bonds, of which countless derivatives exist ranging from the particularly electron-poor to the very electron-rich depending on their substitution pattern, boron-boron double bonds are only now starting to be explored. ${ }^{[1]}$ The parent diborene molecule, $\mathrm{B}_{2} \mathrm{H}_{2}$, which presents an acetylene-like, linear structure and exists in its triplet state, has only been observed transiently by IR and EPR spectroscopy in neon and argon matrices. ${ }^{[2]}$ The successful isolation of otherwise highly reactive $B_{2} R_{2}$ diborenes requires the use of neutral Lewis bases $(L)$, which, by donating into the empty $p$ orbitals at the boron centers, enable the formation of kinetically stable diborene(4) compounds, $[\mathrm{LRB}=\mathrm{BRL}],{ }^{[3]}$ isoelectronic to $\mathrm{R}_{2} \mathrm{C}=\mathrm{CR}_{2}$ alkenes. A couple of Lewis base-free diborenes have also been successfully stabilized at platinum(0) metal centers, where they are bound side-on in a manner reminiscent of transition metal alkyne complexes, and stabilized by additional $\pi$-backdonation from the electron-rich metal center into the empty $\pi_{\perp}$ bonding orbital of the diborene. ${ }^{[4]}$

The first base-stabilized 1,2-dihydrodiborenes, isolated a decade ago by Robinson and co-workers, were by-products of the reduction of $\mathrm{N}$-heterocyclic carbene $(\mathrm{NHC})$ supported tribromoboranes, $\left(\mathrm{I}^{\mathrm{Ar}}\right) \mathrm{BBr}_{3}\left(\mathrm{l}^{\mathrm{Ar}}=\left(1,3-\mathrm{Ar}_{2}\right)\right.$ imidazol-2-ylidene, $\mathrm{Ar}=$ 2,6- ${ }^{\prime} \mathrm{Pr}_{2} \mathrm{C}_{6} \mathrm{H}_{3}$ (Dip), 2,4,6-Me ${ }_{3} \mathrm{C}_{6} \mathrm{H}_{2}$ (Mes), Fig. $1 \mathrm{~A}$ ), resulting from

D. Auerhammer, Dr. M. Arrowsmith, Dr. P. Bissinger, Prof. Dr. H. Braunschweig, ${ }^{,}$Dr. T. Dellermann, Dr. T. Kupfer, C. Lenczyk, Dr. D. K. Roy, Dr. M. Schäfer, Dr. C. Schneider

[a] Institut für Anorganische Chemie, Julius-Maximilians Universität Würzburg, Am Hubland, 97074 Würzburg (Germany)

E-mail: h.braunschweig@uni-wuerzburg.de

[b] Institute for Sustainable Chemistry \& Catalysis with Boron, JuliusMaximilians Universität Würzburg, Am Hubland, 97074 Würzburg (Germany)

Supporting information for this article is given via a link at the end of the document. unwanted radical hydrogen abstraction reactions. ${ }^{[3]} \mathrm{A}$ few years later our group isolated a deep-green 1,2-dibromodiborene from the selective two-electron reduction of the tetrabromodiborane(6) precursor $\left[\left(\mathrm{I}^{\mathrm{Dip}}\right)_{2} \mathrm{~B}_{2} \mathrm{Br}_{4}\right]$ as an intermediate in the synthesis of the first $\mathrm{B}-\mathrm{B}$ triple bond, $\left[\left({ }^{\mathrm{Dip}}\right) \mathrm{B} \equiv \mathrm{B}\left(\mathrm{I}^{\mathrm{Dip}}\right)\right] \cdot{ }^{\left[{ }^{[5]}\right.}$ The targeted synthesis of dihydrodiborenes was only recently achieved with excellent selectivity and yield by the direct $1,2-$ hydrogenation of a NHC-stabilized diboryne, $\left[\left(I^{\text {Dep }}\right) \mathrm{B} \equiv \mathrm{B}\left(\mathrm{I}^{\mathrm{Dep}}\right)\right]$ (Dep = 2,6- $\mathrm{Et}_{2} \mathrm{C}_{6} \mathrm{H}_{3}$, Fig. 1A), and a cyclic (alkyl)(amino)carbene (cAAC)-supported diboracumulene, [(CAAC)B=B(cAAC)] (cAAC $=$ 1-Dip-(3,3,5,5-Me 4 )pyrrolidin-2-ylidene) ${ }^{[6]} \quad$ Thermal decomposition of the bis(tert-butyl)isocyanide adduct of the latter also provided the first 1,2-dicyanodiborene, [(CAAC)B(CN) $]_{2}$, which presents two distinct ${ }^{11} \mathrm{~B}$ NMR shifts due to an unsymmetrical arrangement of the CAAC ligands, one being coplanar with, and the other orthogonal to, the dicyanodiborene core. $^{[7]}$
A) Robinson $(2007,2008)$ Braunschweig (2016)

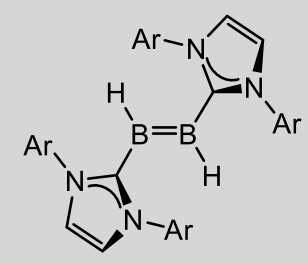

$\mathrm{Ar}=2,6-\mathrm{Pr}_{2} \mathrm{C}_{6} \mathrm{H}_{3}$ (Dip)

$=2,6-\mathrm{Et}_{2} \mathrm{C}_{6} \mathrm{H}_{3}$ (Dep)

$=2,4,6-\mathrm{Me}_{3} \mathrm{C}_{6} \mathrm{H}_{2}$ (Mes)

C) Braunschweig $(2014,2015)$

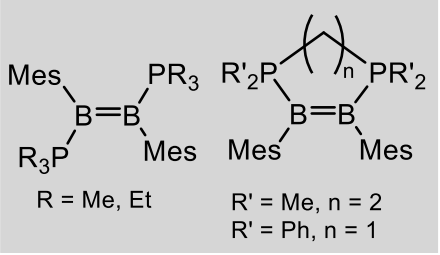

B) Braunschweig (2014)

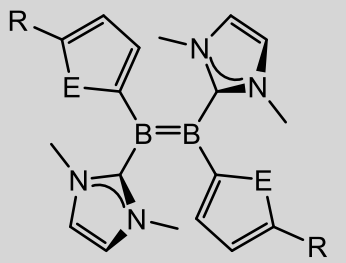

$E=S, R=H(T h)$ $\mathrm{R}=\mathrm{SiMe}_{3}\left(\mathrm{Th}^{\mathrm{tms}}\right)$

$E=O, R=M e$

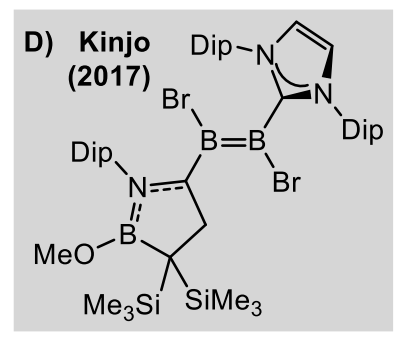

Figure 1. Selection of literature-known Lewis base-stabilized diborenes.

A small range of 1,2-diaryldiborenes has been successfully synthesized using the much smaller 1,3-dimethylimidazol-2ylidene $\left(\mathrm{I}^{\mathrm{Me}}\right)$ ligand, by two-electron reduction of the corresponding aryldichloroboranes, $\left(\mathrm{I}^{\mathrm{Me}}\right) \mathrm{BCl}_{2} \mathrm{Ar} \quad(\mathrm{Ar}=\mathrm{Mes}$, 2,3,5,6- $\mathrm{Me}_{4} \mathrm{C}_{6} \mathrm{H}$ (Dur), 2-thienyl (Th), 5-trimethylsilyl-2-thienyl $\left(\mathrm{Th}^{\mathrm{tms}}\right)$, 5-methyl-2-furyl, Fig. 1B) ${ }^{[8][9]}$ Diborenes of the form $\left[\left(\mathrm{I}^{\mathrm{Me}}\right) \mathrm{BAr}\right]_{2}$ are typically red (Ar = Mes, Dur, 5-methyl-2-furyl) or deep purple $\left(\mathrm{Ar}=\mathrm{Th}, \mathrm{Th}^{\mathrm{tms}}\right)$ in solution. Interestingly, the thienyland furyl-substituted diborenes show a coplanar arrangement of 
the heteroaromatic rings with the diborene core, thus enabling m-electron delocalization over the entire 1,2bis(heteroaryl)diborene framework, ${ }^{[8]}$ whereas the mesityl and duryl groups rotate into orthogonal positions, presumably to relieve the steric strain caused by their ortho-methyl substituents. $^{[9]}$ The only 1,2-dialkyldiborene isolated to date remains the highly electron-rich $\left.\left[{ }^{\mathrm{IPr}}\right) \mathrm{B}^{\mathrm{i}} \mathrm{Pr}\right]_{2} \quad\left(\mathrm{I}^{\mathrm{Pr}}=1,3-\right.$ diisopropylimidazol-2-ylidene). ${ }^{[10]}$ In contrast, phosphinestabilized diborenes are currently only accessible starting from a pre-formed boron-boron bond. The two-electron reduction of 1,2diaryl-1,2-dibromodiboranes(4), $\mathrm{B}_{2} \mathrm{Br}_{2} \mathrm{Ar}_{2}$ ( $\mathrm{Ar}=$ Mes, Dur, 9anthryl) in the presence of two equivalents of $\mathrm{PMe}_{3}$ or $\mathrm{PEt}_{3}$ thus yielded the red-colored bis(phosphino) diborenes, $\left[\left(\mathrm{R}_{3} \mathrm{P}\right) \mathrm{BAr}\right]_{2}(\mathrm{R}$ $=\mathrm{Me}, \mathrm{Et}, \mathrm{Ar}=\mathrm{Mes}$, Fig. 1C; $\mathrm{R}=\mathrm{Me}, \mathrm{Ar}=9$-anthryl $) \cdot{ }^{[11]-[13]}$ While all hitherto mentioned diborenes present a trans-arrangement of their respective anionic and neutral ligands, the use of chelating bis(phosphine) ligands enabled the synthesis of the first cis-1,2diaryldiborenes (Fig. 1C) ${ }^{[12]}$ Most recently, the group of Kinjo succeeded in isolating the first unsymmetrical diborene, supported on one side by a particularly $\pi$-acidic CAAC ligand and on the other by $\mathrm{I}^{\mathrm{Dip}}$ (Fig. 1D), ${ }^{[14]}$ as well as a unique allenic diborene, stabilized by two $\mathrm{PMe}_{3}$ ligands on the terminal boron. ${ }^{[15]}$

With such a limited number of combinations of anionic substituents and neutral donor ligands capable of successfully stabilizing diborenes, there is still little known about their reactivity. Like their alkene relatives, $[\mathrm{LBR}]_{2}$ diborenes form $\pi$ adducts with late transition metals of groups 11 and $12 .^{[9],[16]}$ However, while alkene hydroboration or cycloaddition reactions require a catalyst, these reactions may proceed uncatalyzed with diborenes. Bis(heteroaryl)diborenes of the form $\left[\left(\mathrm{I}^{\mathrm{Me}}\right) \mathrm{BAr}\right]_{2}$, for example, were found to undergo spontaneous hydroboration with catecholborane $\left(\mathrm{Ar}=\mathrm{Th}^{\mathrm{tms}}, 5 \text {-methyl-2-furyl }\right)^{[8]}$ and 9-BBN $\left(\mathrm{Ar}=\mathrm{Th}, \mathrm{Th}^{\mathrm{tms}}\right),{ }^{[17]}$ while the phosphine-stabilized $\left[\left(\mathrm{Me}_{3} \mathrm{P}\right) \mathrm{BMes}\right]_{2}$ underwent photo-induced [2+2] cycloaddition with acetylene. ${ }^{[18]}$ Overall, however, the range of existing diborenes has proven surprisingly ineffective in the activation of small molecules.

The main difference between isoelectronic alkenes and diborenes(4) can be seen in their electronic properties. Theoretical calculations have shown that, although the shape and localization of the frontier orbitals are similar in alkenes and diborenes, the HOMO of ethene lies $4-5 \mathrm{eV}$ below that of known $[\mathrm{LBR}]_{2}$ diborenes, while its HOMO-LUMO gap is two to three times larger, depending on the diborene substitution pattern (Fig. 2). ${ }^{[1]}$ As a result, diborenes, unlike alkenes, are excellent reducing agents, capable of acting as either i) fourelectron reducing agents towards elemental sulfur, by fully cleaving the $\mathrm{B}=\mathrm{B}$ double bond and forming a $\mathrm{B}_{2} \mathrm{~S}_{3}$ heterocycle, ${ }^{[19]}$ or ii) two-electron reducing agents towards the heavier elemental chalcogens by forming three-membered $B_{2} E$ rings $(E=S e, T e),{ }^{[20]}$ or even iii) one-electron reducing agents towards the tropylium cation and 1-mesityl-2,3,4,5tetraphenylborole $\left(\mathrm{MesBC}_{4} \mathrm{Ph}_{4}\right)$ to form diborene radical cations. ${ }^{[10],[11]}$

The substitution pattern of the diborene core plays a significant role in tuning this redox reactivity (Fig. 2). Thus switching from $\mathrm{PMe}_{3}$ to the better $\sigma$-donor and slightly better $\pi$ acceptor $\mathrm{I}^{\mathrm{Me}}$, whilst retaining mesityl or duryl anionic substituents, induces an increase in the energy of the HOMO concomitant with a lowering of the energy of the LUMO, thereby reducing the
HOMO-LUMO gap by ca. $0.8 \mathrm{eV} .^{[11]}$ Similarly, switching from $\mathrm{PMe}_{3}$ to the more $\pi$-acidic chelating 1,2bis(diphenylphosphino)methane ligand only induces a lowering of the LUMO energy, thereby also reducing the HOMO-LUMO gap. ${ }^{[12]}$ Conversely, changing the anionic substituent from electron-withdrawing duryl to slightly electron-releasing isopropyl groups, and switching from $\mathrm{I}^{\mathrm{Me}}$ to the even better $\sigma$-donor $\mathrm{I}^{\mathrm{IPr}}$, causes a ca. 0.9 and $1.2 \mathrm{eV}$ increase in the energy of the HOMO and LUMO, respectively, thereby making $\left[\left(I^{\mathrm{IPr}}\right) \mathrm{B}^{i} \mathrm{Pr}\right]_{2}$ the most electron-rich diborene yet, capable even of reducing the borole $\mathrm{MesBC}_{4} \mathrm{Ph}_{4}{ }^{[10]}$

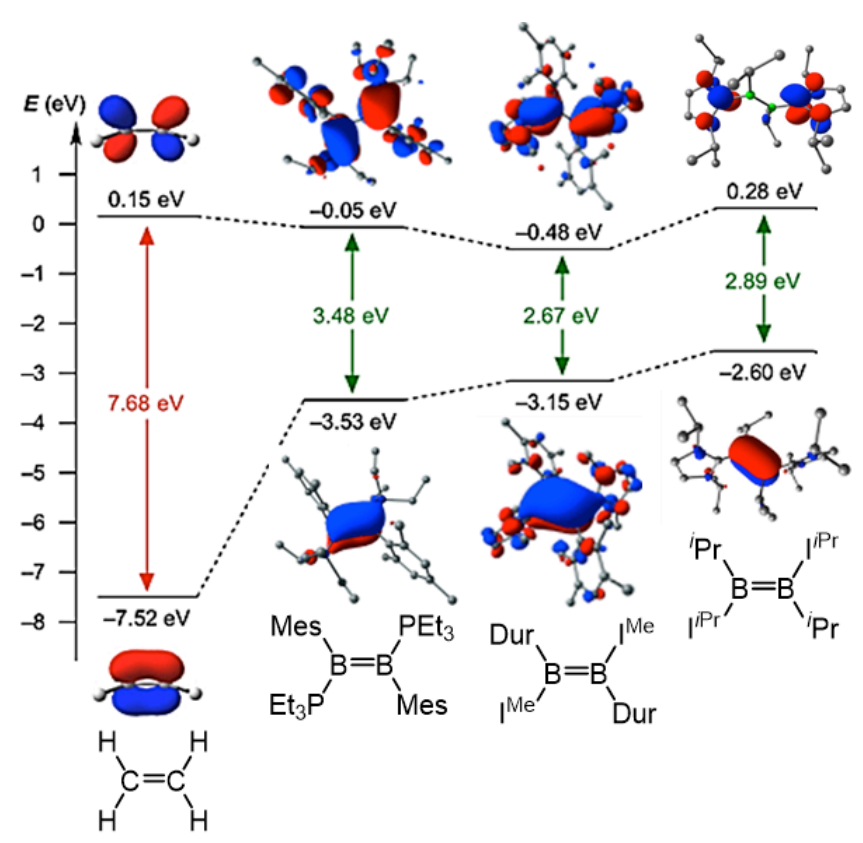

Figure 2. Comparison of the relative HOMO and LUMO energies and gaps $(\mathrm{eV})$ of $\left[\left(\mathrm{Et}_{3} \mathrm{P}\right) \mathrm{BMes}\right]_{2}\left[\left(\mathrm{I}^{\mathrm{Me}}\right) \mathrm{BDur}\right]_{2}$ and $\left[\left(\mathrm{I}^{\mathrm{IPr}}\right) \mathrm{B}^{\prime} \mathrm{Pr}\right]_{2}$ with ethene optimized at the B3LYP/6-311G* level (adapted from reference [10]).

Table 1. TEP, ${ }^{31} \mathrm{P}$ NMR shift of the NHC-PPh adduct (recorded in $\mathrm{C}_{6} \mathrm{D}_{6}$, except for $\mathrm{I}^{\mathrm{MeMe}}-\mathrm{PPh}$, which was recorded in $\mathrm{d}_{8}$-thf) and $\% V_{\text {bur }}$ values for selected $\mathrm{NHCs}$.

\begin{tabular}{|c|c|c|c|c|c|c|}
\hline & NHC & $\mathbf{R}^{1}$ & $\mathbf{R}^{2}$ & $\begin{array}{l}\text { TEP } \\
\left(\mathrm{cm}^{-1}\right)^{[25]}\end{array}$ & $\begin{array}{l}\delta\left({ }^{31} \mathrm{P}\right) \\
(\mathrm{ppm})^{[22][25]}\end{array}$ & $\% V_{\text {bur }}^{[24]}$ \\
\hline & $\mathrm{I}^{\mathrm{Me}}$ & $\mathrm{Me}$ & $\mathrm{H}$ & 2054.1 & -49.1 & 26.3 \\
\hline $\mathrm{R}^{2}$ & $I^{\mathrm{MeMe}}$ & $\mathrm{Me}$ & $\mathrm{Me}$ & 2051.7 & -53.5 & 26.2 \\
\hline $\mathrm{N} \smile \mathrm{N}=$ & $\mathrm{I}^{\mathrm{iPr}}$ & ${ }^{i} \mathrm{Pr}$ & $\mathrm{H}$ & 2051.5 & -61.2 & 27.5 \\
\hline & $\mathrm{I}^{\mathrm{Mes}}$ & Mes & $\mathrm{H}$ & 2050.5 & -23.0 & 36.5 \\
\hline
\end{tabular}

In order to probe the electronic and steric influence of both neutral and anionic ligands on the diborene core in a more systematic fashion, and hopefully increase the reactivity of diborenes towards small molecules, we set out to synthesize a family of NHC-stabilized 1,2-bis(thienyl)diborene derivatives. The electronic properties of $\mathrm{NHCs}$ are commonly quantified by the Tolman Electronic Parameter (TEP) ${ }^{[21]}$ which corresponds to the IR stretching frequency of the carbonyl ligands in complexes of the form $\left[\mathrm{Ni}(\mathrm{CO})_{3}(\mathrm{NHC})\right]$ : the more $\sigma$-donating and/or less $\pi-$ accepting the NHC ligand, the higher the value of the TEP. 
Furthermore, Bertrand and co-workers have shown that the ${ }^{31} \mathrm{P}$ NMR shifts of NHC phenylphosphinidene adducts provide a reliable indicator of the relative $\pi$-acceptor strength of NHCs: the more $\pi$-accepting the carbene ligand, the further downfield the ${ }^{31} \mathrm{P}$ NMR shift. ${ }^{[2]}$ The steric properties of NHCs can be conveniently compared using the percent buried volume $\left(\% V_{\text {bur }}\right),{ }^{[23]}$ defined here as the percentage of a $3.5 \AA$ radius sphere around the metal center that is occupied by the ligand, assuming a metal-ligand distance of $2 \AA$. $I^{\mathrm{Me}}, \mathrm{I}^{\mathrm{MeMe}}((1,3,4,5-$ $\mathrm{Me}_{4}$ )imidazol-2-ylidene) $\mathrm{I}^{\mathrm{IPr}}$ and $\mathrm{I}^{\mathrm{Mes}}$ were thus selected for their increasing steric bulk ${ }^{[24]}$ and decreasing TEPs, ${ }^{[25]}$ as well as for the increased $\pi$-acceptor strength going from $\mathrm{I}^{\mathrm{Me}}$ to $\mathrm{I}^{\mathrm{MeMe}}$ to $\mathrm{I}^{\mathrm{iPr}}$, ${ }^{[22][25]}$ as summarized in Table 1.

For the anionic ligands, thienyl substituents were chosen for their ease of derivatization at the C2-, C3- and C5-positions. Substitution of a 2-thienyl ligand with a diarylamino group at the C5-position was deemed to potentially increase its m-electrondonating ability, thus making the diborene unit even more electron-rich, and hopefully more reactive. Prompted by studies from the groups of Jäkle and Weber on the optoelectronic influence of diarylamino-substitution on bithienyl- and thienylboranes, ${ }^{[27][28]} 5$-diphenylamino-2-thienyl $\left(\mathrm{Th}^{\mathrm{dpa}}\right)$ and $5-(\mathrm{N}$ carbazolyl)-2-thienyl) ( $\mathrm{Th}^{\text {car }}$ ) were selected, alongside the parent Th group, the remotely substituted $\mathrm{Th}^{\text {tms }}$ group and the sterically encumbered, vicinally substituted 2,5-dimethyl-3-thienyl ( $\mathrm{Th}^{\mathrm{Me} 2}$ ) group.

\section{Results and Discussion}

A series of (dihalo)thienylborane derivatives, $\mathrm{BX}_{2} \mathrm{Ar}(\mathrm{X}=\mathrm{Cl}, \mathrm{Ar}=$ $\mathrm{Th}, \mathrm{Th}^{\mathrm{tms}}, \mathrm{Th}^{\mathrm{Me} 2} ; \mathrm{X}=\mathrm{Br}, \mathrm{Ar}=\mathrm{Th}^{\mathrm{dpa}}, \mathrm{Th}^{\mathrm{car}}$ ) was synthesized by $\mathrm{Me}_{3} \mathrm{SiX}$ elimination from the corresponding trimethylsilylthiophene precursors with $\mathrm{BX}_{3}$. Subsequent addition of various $\mathrm{NHCs}$ in hexanes at low temperature yielded the corresponding adducts, $(\mathrm{NHC}) \mathrm{BX}_{2} \mathrm{Ar}\left(\mathrm{NHC}=\mathrm{I}^{\mathrm{Me}}, \mathrm{X}_{2} \mathrm{Ar}=\mathrm{Br}_{2} \mathrm{Th}^{\mathrm{dpa}}\right.$ $\mathrm{Br}_{2} \mathrm{Th}^{\text {car }} ; \mathrm{NHC}=l^{\mathrm{MeMe}}, \mathrm{I}^{\mathrm{PPr}}, \mathrm{X}_{2} \mathrm{Ar}=\mathrm{Cl}_{2} \mathrm{Th}, \mathrm{Cl}_{2} \mathrm{Th}^{\text {tms }}, \mathrm{Th}^{\mathrm{Me} 2}, \mathrm{Br}_{2} \mathrm{Th}^{\text {dpa }}$; $\mathrm{NHC}=I^{\mathrm{Mes}}, \mathrm{X}_{2} \mathrm{Ar}=\mathrm{Cl}_{2} \mathrm{Th}$ ) in good to excellent yields as colorless solids (Scheme 1 ).

The dichloro derivatives all displayed ${ }^{11} \mathrm{~B}$ NMR shifts in the region of 0 to $-1.5 \mathrm{ppm}$, similar to related $\left(\mathrm{I}^{\mathrm{Me}}\right) \mathrm{BX}_{2} \mathrm{Ar}$ species (ca. $-1.7 \mathrm{ppm}),{ }^{\left[{ }^{[8]}\right.}$ whereas the dibromo derivatives appeared further upfield, around $-8 \mathrm{ppm}$ (Table 2), as expected from the less electron-withdrawing character of $\mathrm{Br}$ versus $\mathrm{Cl}$. The ${ }^{13} \mathrm{C}$ NMR resonances of the boron-bound $\mathrm{NHC}$ and thienyl carbon atoms, broadened by coupling to the quadrupolar boron nucleus, could, in most cases, be detected by HMBC around 159 and 155 ppm, respectively. In contrast to the other adducts, all three $\mathrm{Th}^{\mathrm{dpa}}$ derivatives proved unstable in solution, undergoing ca. $10 \%$ decomposition over 18 hours at room temperature, thus precluding the acquisition of clean NMR spectra. In the solid state and under inert atmosphere, however, these compounds remained stable over several weeks. While the decomposition mechanism remains unclear, it is noteworthy that the $N$ carbazolyl-derivative, $\left(l^{\mathrm{Me}}\right) \mathrm{BBr}_{2} \mathrm{Th}^{\text {car }}$, which is formally the fusedring analogue of $\left(\mathrm{I}^{\mathrm{Me}}\right) \mathrm{BBr}_{2} \mathrm{Th}^{\mathrm{dpa}}$, was stable in solution.

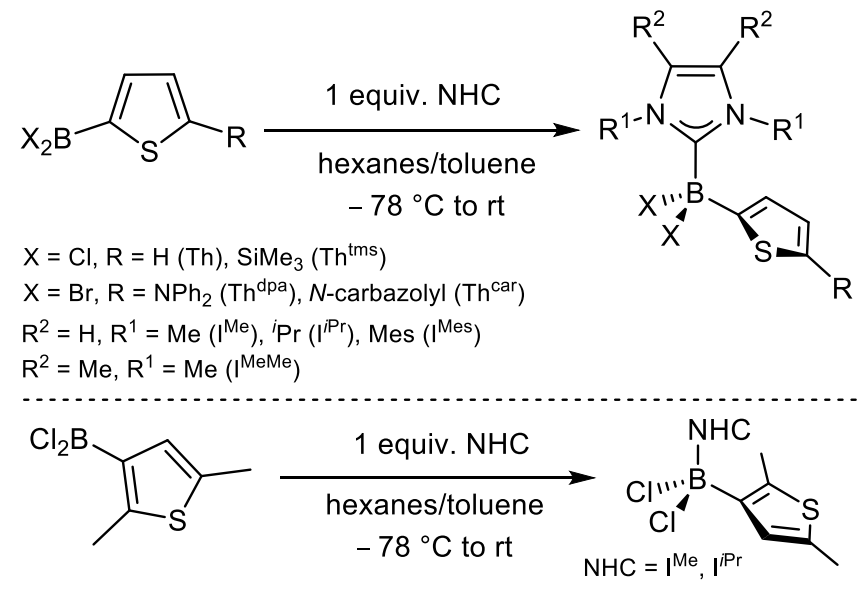

Scheme 1. Synthesis of NHC-supported (dihalo)thienylborane precursors.

The $(\mathrm{NHC}) \mathrm{BX}_{2} \mathrm{Th}^{\mathrm{R}}$ adducts readily crystallized from saturated toluene solutions stored at room temperature, providing single crystals suitable for X-ray crystallographic analysis in most cases. Fig. 3 displays the solid-state structures of $\left(\mathrm{l}^{\mathrm{MeMe}}\right) \mathrm{BCl}_{2} \mathrm{Th}$, $\left(\mathrm{I}^{\mathrm{iPr}}\right) \mathrm{BCl}_{2} \mathrm{Th}^{\mathrm{tms}}, \quad\left(\mathrm{I}^{\mathrm{MeMe}}\right) \mathrm{BBr}_{2} \mathrm{Th}^{\mathrm{dpa}}$ and $\left(\mathrm{I}^{\mathrm{Me}}\right) \mathrm{BBr}_{2} \mathrm{Th}^{\mathrm{car}}$ (see Supporting Information for the solid-state structures of

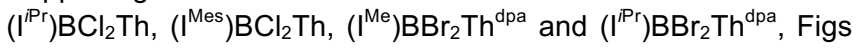
S44-S45). Relevant bond lengths and angles for all crystallographically characterized adducts are listed in Table 2. The $B-C_{N H C}$ bond lengths $(1.613(3)-1.632(3) \AA)$ are comparable to that in $\left(l^{\mathrm{Me}}\right) \mathrm{BCl}_{2} \mathrm{Th}^{\text {tms }}(1.619(2) \AA)^{[8]}$ and typical of $\mathrm{C}_{\mathrm{NHC}}-\mathrm{B} \sigma$-donor interactions in $\mathrm{sp}^{3}$ boranes. The planar thiophene rings are near perpendicular to the $\mathrm{NHC}$ ring (torsion angle $\left.(\mathrm{N} 1, \mathrm{~B} 1, \mathrm{C} 10, \mathrm{~S} 1) 74.6(8)-88.2(2)^{\circ}\right)$. It is noteworthy that, in the case of the $\mathrm{Th}^{\mathrm{car}}$ and $\mathrm{Th}^{\mathrm{dpa}}$ derivatives, the plane of the $\mathrm{sp}^{2}$-hybridized nitrogen atom N3 is far from coplanar with that of the thiophene ring, with torsion angles of ca. $45-49^{\circ}$ for the $\mathrm{Th}^{\mathrm{dpa}}$ analogues, which present a propeller-like arrangement of the three N3-aryl substituents, and an even wider torsion angle of ca. $77^{\circ}$ for the $\mathrm{Th}^{\mathrm{car}}$ derivative.

The reduction of all nine NHC-stabilized (dihalo)thienylboranes was conducted at room temperature in toluene with a large excess of $\mathrm{KC}_{8}$ (Scheme 2). The reduction of $\mathrm{I}^{\mathrm{Me}}$-, $\mathrm{I}^{\mathrm{MeMe}}$ - and $\mathrm{I}^{\mathrm{Pr}}$-stabilized precursors was accompanied by a deep-purple-to-pink coloration indicative of diborene formation. In contrast, the reaction of $\left(\mathrm{I}^{\mathrm{Mes}}\right) \mathrm{BCl}_{2} \mathrm{Th}$ with $\mathrm{KC}_{8}$ first turned brown, then colorless within a couple of hours at room temperature. While ${ }^{11} \mathrm{~B}$ NMR spectra of the crude reaction mixture indicated full consumption of the borane starting material, the reaction yielded an intractable mixture of products, the major one displaying a broad ${ }^{11} \mathrm{~B} N M R \mathrm{BH}$ doublet at around $-13 \mathrm{ppm}$, indicating an $\mathrm{sp}^{3}$-hybridized hydroborane, most likely resulting from $\mathrm{C}-\mathrm{H}$ bond activation by an intermediate borylene species. Although repeated attempts to isolate any of these $\mathrm{C}-\mathrm{H}$ activation products failed, the species observed at $\delta_{11 \mathrm{~B}}-13 \mathrm{ppm}$ most likely results from the intramolecular insertion of a borylene into a $\mathrm{C}-\mathrm{H}$ bond of an ortho-methyl group on $\mathrm{I}^{\text {Mes }}$. Such intramolecular $\mathrm{C}-\mathrm{H}$ activation products have been repeatedly observed when attempting to reduce particularly sterically encumbered boranes presenting pendant Mes or Dip groups, ${ }^{[29]}$ or when heating sterically encumbered isolated borylenes. ${ }^{[30]}$ 


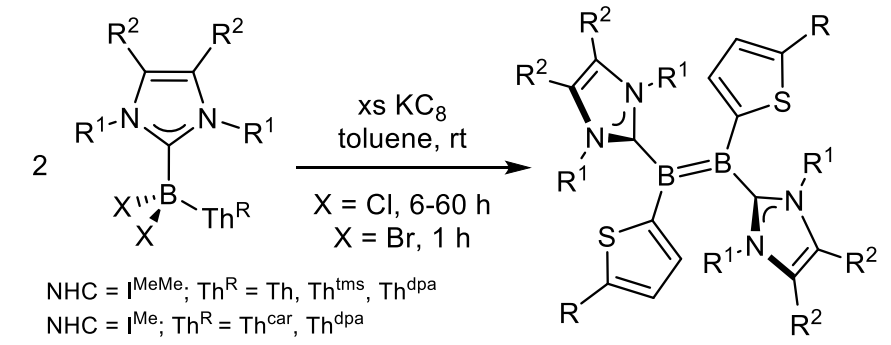
$\mathrm{NHC}=\mathrm{I}^{\mathrm{Me}} ; \mathrm{Th}^{\mathrm{R}}=\mathrm{Th}^{\mathrm{car}}, \mathrm{Th}^{\mathrm{dpa}}$ $\mathrm{NHC}=\mathrm{I}^{\mathrm{IPr}} ; \mathrm{Th}^{\mathrm{R}}=\mathrm{Th}, \mathrm{Th}^{\mathrm{tms}}$<smiles></smiles>

Scheme 2. Synthesis of NHC-supported 1,2-dithienylborenes.

For the dibromoborane precursors, monitoring of the reactions by ${ }^{11} \mathrm{~B}$ NMR spectroscopy indicated nearly full consumption of the borane within one hour, after which the suspendion was promptly filtered to remove remaining $\mathrm{KC}_{8}$ and the $\mathrm{KBr}$ byproduct. This was done to avoid side reactions such as $\mathrm{C}-\mathrm{H}$ activations, which increased upon longer reaction times, as the concentration of borylene monomers decreased, favoring intramolecular reactions over dimerization. For the dichloroborane precursors, longer reaction times of up to 60 hours were required to achieve full consumption of the borane, and the amount of $\mathrm{C}-\mathrm{H}$ activation byproducts was lower than for the dibromoborane-based reactions.

After filtration and removal of volatiles, the resulting diborenes were recrystallized from pentane or hexanes as purple-red solids, all presenting broad ${ }^{11} \mathrm{~B}$ NMR resonances between 20.2 and $22.5 \mathrm{pppm}$ in $\mathrm{C}_{6} \mathrm{D}_{6}$ (Table 3), similar to those of $\mathrm{I}^{\mathrm{Me}}$-stabilized Th- and $\mathrm{Th}^{\text {tms }}$-substituted diborenes (21.3 and $22.4 \mathrm{ppm}$, respectively) ${ }^{[8]}$ Exchanging $\mathrm{I}^{\mathrm{Me}}$ for the slightly better $\sigma$-donor and $\pi$-acceptor ligands $\mathrm{I}^{\mathrm{MeMe}}$ or $\mathrm{I}^{\mathrm{iPr}}$ seemed to have no effect on the ${ }^{11} \mathrm{~B}$ NMR shift of the diborene, nor did methyl, trimethylsilyl or diarylamino substituents on the thiophene ring. The ${ }^{13} \mathrm{C}$ NMR resonances of the boron-bound $\mathrm{C}_{\mathrm{NHC}}$ and $\mathrm{C}_{\mathrm{Th}}$ atoms, both highly broadened, could be detected, in most cases, by $\mathrm{HMBC}$ at around $172 \mathrm{ppm}$ and $159-168 \mathrm{ppm}$, respectively, significantly downfield from those of the borane precursors (vide supra). This reflects the strong $\pi$-conjugation over the dithienyldiborene framework and the strong $\sigma$-donor properties of the NHC ligands. Unlike the other diborenes, which proved

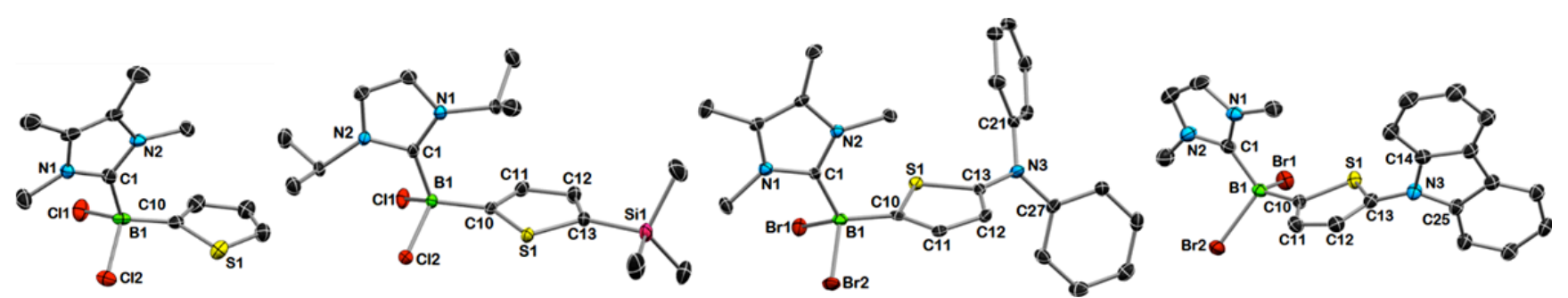

Figure 3. Crystallographically determined solid-state structures of (from left to right) $\left(l^{\mathrm{MeMe}}\right) \mathrm{BCl}_{2} \mathrm{Th},\left(I^{\mathrm{IPr}}\right) \mathrm{BCl}_{2} \mathrm{Th}^{\mathrm{tms}},\left(I^{\mathrm{MeMe}}\right) \mathrm{BBr}_{2} \mathrm{Th}^{\mathrm{dpa}}$ and $\left(I^{\mathrm{Me}}\right) \mathrm{BBr}_{2} \mathrm{Th}^{\mathrm{car}}$. Atomic displacement ellipsoids depicted at the $50 \%$ probability level. Hydrogen atoms omitted for clarity.

Table 2. ${ }^{11} B$ NMR shifts $(\mathrm{ppm})$, selected bond lengths $(\AA)$ and angles $\left({ }^{\circ}\right)$ for crystallographically characterized NHC-supported (dihalo)thienylboranes.

\begin{tabular}{|c|c|c|c|c|c|c|c|}
\hline & $\left(\mathrm{I}^{\mathrm{MeMe}}\right) \mathrm{BCl}_{2} \mathrm{Th}$ & $\left(\mathrm{I}^{\mathrm{iPr}}\right) \mathrm{BCl}_{2} \mathrm{Th}$ & $\left(\mathrm{I}^{\mathrm{iPr}}\right) \mathrm{BCl}_{2} \mathrm{Th}^{\mathrm{tms}}$ & $\left(\mathrm{I}^{\mathrm{Me}}\right) \mathrm{BBr}_{2} \mathrm{Th}^{\mathrm{dpa}}$ & $\left(I^{\mathrm{MeMe}}\right) \mathrm{BBr}_{2} \mathrm{Th}^{\mathrm{dpa}}$ & $\left(\left(^{i P r}\right) \mathrm{BBr}_{2} \mathrm{Th}^{\mathrm{dpa}}\right.$ & $\left(I^{\mathrm{Me}}\right) \mathrm{BBr}_{2} \mathrm{Th}^{\mathrm{car}}$ \\
\hline$\delta\left({ }^{11} \mathrm{~B}\right)$ & -1.3 & -1.4 & -0.2 & -8.0 & -7.3 & -7.4 & -8.2 \\
\hline $\mathrm{B} 1-\mathrm{C} 1$ & $1.629(8)$ & $1.625(3)$ & $1.632(3)$ & $1.619(3)$ & $1.613(3)$ & $1.619(6)$ & $1.613(3)$ \\
\hline B1-C10 & $1.586(9)$ & $1.588(3)$ & $1.590(3)$ & $1.575(4)$ & $1.584(3)$ & $1.585(6)$ & $1.586(3)$ \\
\hline $\mathrm{B} 1-\mathrm{X} 1^{\mathrm{a}}$ & $1.887(7)$ & $1.893(1)$ & $1.885(2)$ & $2.075(3)$ & $2.062(3)$ & $2.059(5)$ & $2.079(2)$ \\
\hline $\mathrm{B} 1-\mathrm{X} 2^{\mathrm{a}}$ & $1.905(7)$ & $1.895(1)$ & $1.9056(18)$ & $2.054(2)$ & $2.077(3)$ & $2.081(5)$ & $2.038(3)$ \\
\hline $\mathrm{N} 1-\mathrm{C} 1-\mathrm{N} 2$ & $104.9(5)$ & $105.58(15)$ & $105.34(15)$ & $105.6(2)$ & $105.16(18)$ & $105.4(3)$ & $104.83(19)$ \\
\hline C1-B1-C10 & $116.5(5)$ & 118.81(16) & $116.19(15)$ & $117.4(2)$ & 117.93(18) & $119.0(3)$ & $115.75(18)$ \\
\hline $\mathrm{C} 1-\mathrm{B} 1-\mathrm{X} 1^{\mathrm{a}}$ & $107.5(4)$ & $105.72(14)$ & $107.26(13)$ & $106.94(15)$ & $106.71(16)$ & $107.4(3)$ & $108.01(15)$ \\
\hline $\mathrm{C} 1-\mathrm{B} 1-\mathrm{X} 2^{\mathrm{a}}$ & $105.9(4)$ & 106.16(14) & $108.83(13)$ & $106.47(15)$ & $106.77(15)$ & $105.9(3)$ & $107.02(15)$ \\
\hline$(\mathrm{N} 1, \mathrm{~B} 1, \mathrm{C} 10, \mathrm{~S} 1)^{\mathrm{b}}$ & $74.6(8)$ & $87.3(6)$ & $84.1(1)$ & $78.0(3)$ & $82.0(3)$ & $73.8(6)$ & $88.2(2)$ \\
\hline$(\mathrm{C} 14 / 21, \mathrm{~N} 3, \mathrm{C} 13, \mathrm{~S} 1)^{\mathrm{C}}$ & - & - & - & $45.2(3)$ & $49.1(3)$ & $64.4(4)$ & $77.1(3)$ \\
\hline
\end{tabular}

${ }^{\mathrm{a}} \mathrm{X}=\mathrm{Cl}, \mathrm{Br}$; ${ }^{\mathrm{b}}$ Torsion angle between the planes of the $\mathrm{NHC}$ and thiophene rings; ${ }^{\mathrm{c}}$ Torsion angle between the plane of the sp ${ }^{2}$ triarylamino residue and the thiophene ring: $(\mathrm{C} 14, \mathrm{~N} 3, \mathrm{C} 13, \mathrm{~S} 1)$ for $\left(\mathrm{I}^{\mathrm{Me}}\right) \mathrm{BBr}_{2} \mathrm{Th}^{\text {car }}$ and $\left(\mathrm{I}^{\mathrm{iPr}}\right) \mathrm{BBr}_{2} \mathrm{Th}^{\mathrm{dpa}},(\mathrm{C} 21, \mathrm{~N} 3, \mathrm{C} 13, \mathrm{~S} 1)$ for $\left(\mathrm{I}^{\mathrm{Me}}\right) \mathrm{BBr}_{2} \mathrm{Th}^{\mathrm{dpa}}$ and $\left(\mathrm{I}^{\mathrm{MeMe}}\right) \mathrm{BBr}_{2} \mathrm{Th}^{\text {dpa }}$. 


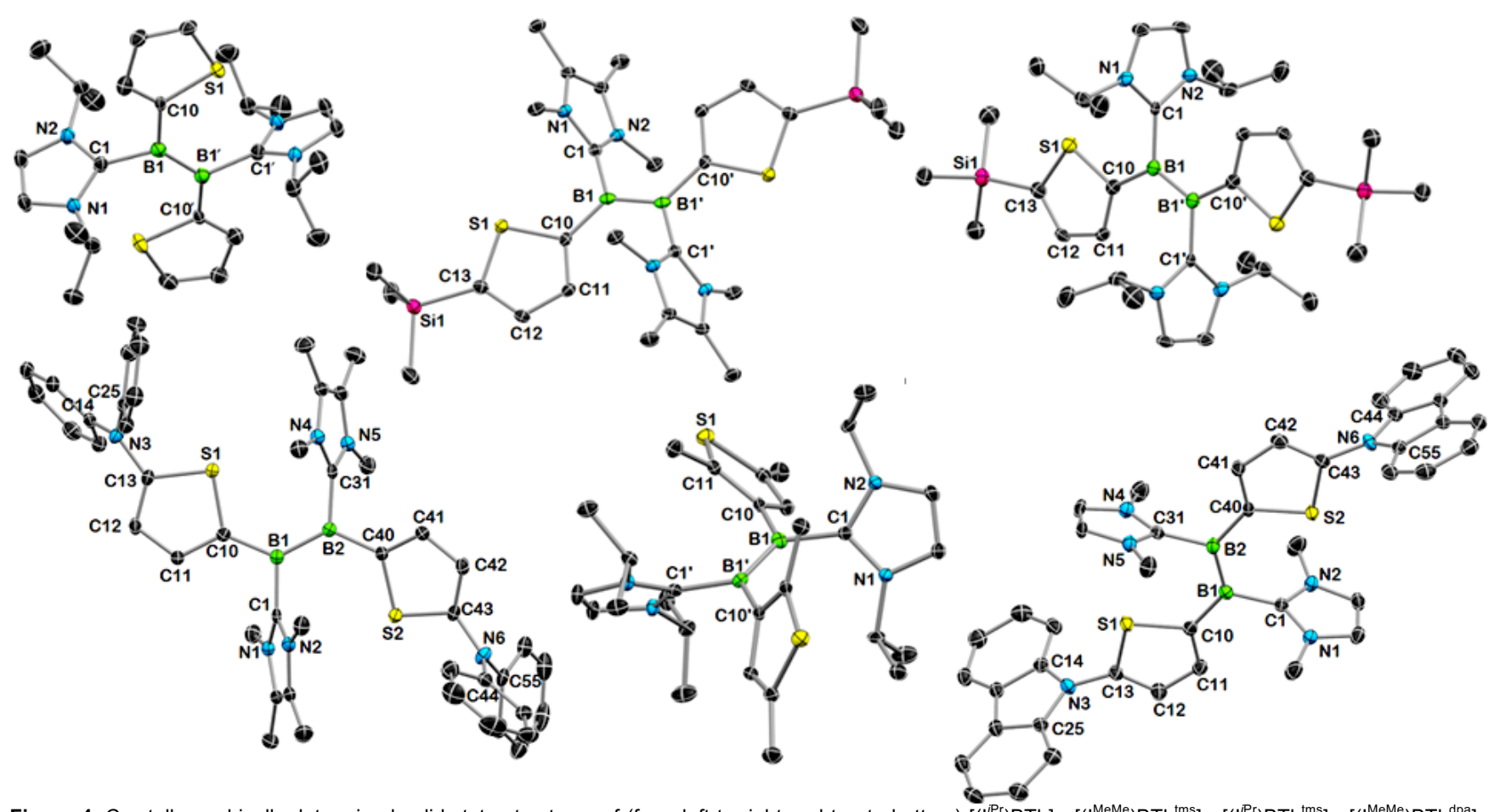

Figure 4. Crystallographically determined solid-state structures of (from left to right and top to bottom) $\left[\left(I^{\mathrm{IPr}}\right) \mathrm{BTh}_{2},\left[\left(\mathrm{I}^{\mathrm{MeMe}}\right) \mathrm{BTh} \mathrm{h}^{\mathrm{tms}}\right]_{2},\left[\left(\mathrm{I}^{\mathrm{Pr}}\right) \mathrm{BTh}{ }^{\mathrm{tms}}\right]_{2},\left[\left(\mathrm{I}^{\mathrm{MeMe}}\right) \mathrm{BTh} \mathrm{dpa}_{2}{ }_{2}\right.\right.$, $\left[\left(I^{\mathrm{Pr}}\right) \mathrm{BTh}^{\mathrm{Me} 2}\right]_{2}$ and $\left[\left(\mathrm{I}^{\mathrm{Me}}\right) \mathrm{BTh}{ }^{\mathrm{car}}\right]_{2}$. Atomic displacement ellipsoids depicted at the $50 \%$ probability level. Hydrogen atoms omitted for clarity.

Table 3. ${ }^{11} B$ NMR shifts $(\mathrm{ppm})$, selected bond lengths $(\AA)$ and angles $\left({ }^{\circ}\right)$ for NHC-supported crystallographically characterized 1,2-dithienyldiborenes.

\begin{tabular}{|c|c|c|c|c|c|c|c|}
\hline & {$\left[\left(\mathrm{l}^{\mathrm{MeMe}}\right) \mathrm{BTh}\right]_{2}$} & {$\left[\left(I^{\text {iPr }}\right) B T h\right]_{2}$} & {$\left[\left(I^{\mathrm{MeMe}}\right) \mathrm{BTh}^{\mathrm{tms}}\right]_{2}$} & {$\left[\left(\mathbf{l}^{\mathrm{IPr}}\right) \mathrm{BTh}^{\mathrm{tms}}\right]_{2}$} & {$\left[\left(\mathrm{I}^{\mathrm{IPr}}\right) \mathrm{BTh}^{\mathrm{Me} 2}\right]_{2}$} & {$\left[\left(1^{\mathrm{MeMe}}\right) B \mathrm{BTh}^{\mathrm{dpa}}\right]_{2}^{\mathrm{e}}$} & {$\left[\left(\mathrm{I}^{\mathrm{Me}}\right) \mathrm{BTh}^{\mathrm{car}}\right]_{2}{ }^{\mathrm{e}}$} \\
\hline$\delta\left({ }^{11} \mathrm{~B}\right)$ & 22.1 & 20.2 & 20.9 & 20.7 & 20.0 & 22.5 & 22.2 \\
\hline $\mathrm{B} 1-\mathrm{C} 1$ & $1.593(3)$ & $1.603(3)$ & $1.585(4)$ & $1.588(5)$ & $1.577(3)$ & $1.582(2)$ & $1.593(5)$ \\
\hline $\mathrm{B} 1-\mathrm{C} 10$ & $1.563(3)$ & $1.560(5)$ & $1.565(4)$ & $1.557(6)$ & $1.589(3)$ & $1.559(2)$ & $1.556(5)$ \\
\hline B1-B1' & $1.576(4)$ & $1.603(4)$ & $1.592(6)$ & $1.587(9)$ & $1.583(5)$ & $1.592(2)$ & $1.600(4)$ \\
\hline $\mathrm{N} 1-\mathrm{C} 1-\mathrm{N} 2$ & $104.0(2)$ & $104.95(16)$ & $104.2(2)$ & 104.3(3) & $104.26(18)$ & $104.50(12)$ & $104.5(3)$ \\
\hline C1-B1-C10 & $114.83(18)$ & $109.6(2)$ & $117.3(2)$ & $114.2(3)$ & $113.23(19)$ & $112.82(12)$ & $111.9(3)$ \\
\hline C1-B1-B1' & $117.6(2)$ & $118.9(2)$ & $117.7(3)$ & $117.6(5)$ & $119.5(3)$ & $117.63(12)$ & 119.1(3) \\
\hline C10-B1-B1' & $127.6(2)$ & $130.6(3)$ & $125.0(3)$ & $128.1(5)$ & $122.9(4)$ & $129.46(13)$ & $129.0(3)$ \\
\hline$\left(\mathrm{C} 1, \mathrm{~B} 1, \mathrm{~B} 1^{\prime}, \mathrm{C} 10^{\prime}\right)^{\mathrm{a}}$ & $0.0(3)$ & $2.7(4)$ & $0.7(5)$ & $0.9(7)$ & $4.2(3)$ & $3.7(2), 5.0(2)$ & $0.1(5), 0.6(5)$ \\
\hline$\left(\mathrm{B} 1^{\prime}, \mathrm{B} 1, \mathrm{C} 10, \mathrm{~S} 1\right)^{\mathrm{b}}$ & $0.9(2)$ & $0.3(5)$ & $20.6(3)$ & $6.4(4)$ & $51.2(3)$ & $5.1(2), 22.7(2)$ & $0.6(5), 1.8(5)$ \\
\hline$\left(\mathrm{B} 1^{\prime}, \mathrm{B} 1, \mathrm{C} 1, \mathrm{~N} 1\right)^{\mathrm{C}}$ & $89.3(3)$ & $77.9(3)$ & $76.5(3)$ & $83.0(5)$ & $51.7(3)$ & $72.9(2), 65.1(2)$ & $82.4(4), 79.3(4)$ \\
\hline$(\mathrm{C} 14, \mathrm{~N} 3, \mathrm{C} 13, \mathrm{~S} 1)^{\mathrm{d}}$ & - & - & - & - & - & $73.6(1), 78.1(1)$ & $79.4(4), 83.5(4)$ \\
\hline
\end{tabular}

${ }^{a}$ Torsion angle $\left(\mathrm{C} 1, \mathrm{~B} 1, \mathrm{~B} 1{ }^{\prime}, \mathrm{C} 10^{\prime}\right)$ for Th- and $\mathrm{Th}^{\text {tms }}$-substituted diborenes, torsion angle $(\mathrm{C} 1, \mathrm{~B} 1, \mathrm{~B} 2, \mathrm{C} 40)$ for $\mathrm{Th}^{\mathrm{dpa}}{ }^{\mathrm{a}}$ and $\mathrm{Th}^{\mathrm{car}}$-substituted diborenes; ${ }^{\mathrm{b}} \mathrm{Torsion}$ angle $\left(\mathrm{B} 11^{\prime}, \mathrm{B} 1, \mathrm{C} 1, \mathrm{~N} 1\right)$ for $\mathrm{Th}$ - and $\mathrm{Th}^{\text {tms }}$-substituted diborenes, torsion angle $(\mathrm{B} 2, \mathrm{~B} 1, \mathrm{C} 1, \mathrm{~N} 1)$ for $\mathrm{Th}^{\text {dpa }}$ - and $\mathrm{Th}^{\text {car }}$-substituted diborenes; ${ }^{\mathrm{c}}$ Torsion angle $\left(B 1{ }^{\prime}, B 1, C 10, S 1\right)$ for Th- and $\mathrm{Th}^{\text {tms }}$-substituted diborenes, torsion angle $(B 2, B 1, C 10, S 1)$ for $\mathrm{Th}^{\text {dpa }}$ - and $\mathrm{Th}^{\text {car }}$-substituted diborenes; ${ }^{\mathrm{d}}{ }^{\text {Torsion }}$ angle between the plane of the $\mathrm{sp}^{2}$ triarylamino residue and the thiophene ring; ${ }^{e}$ Bond lengths and angles given for the B1 moiety of the molecule only, torsion angles given for both molecule moieties.

stable in solution over several days, one of the trimethylsilyl derivatives, $\left[\left(\mathrm{I}^{\mathrm{MeMe}}\right) \mathrm{BTh}^{\mathrm{tms}}\right]_{2}$, and both diphenylamino derivatives, $\left[\left(\mathrm{I}^{\mathrm{Me}}\right) \mathrm{BTh}^{\mathrm{dpa}}\right]_{2}$ and $\left[\left(\mathrm{I}^{\mathrm{MeMe}}\right) \mathrm{BTh}{ }^{\mathrm{dpa}}\right]_{2}$, underwent $5-10 \%$ decomposition in solution under argon over a period of 24 hours, precluding the acquisition of clean NMR data. The decomposition process for these species remains unclear. All ten diborenes proved extremely soluble even in pentanes and single crystals for eight of them, $[(\mathrm{NHC}) \mathrm{BAr}]_{2}\left(\mathrm{NHC}=\mathrm{I}^{\mathrm{Me}}, \mathrm{Ar}=\right.$ $\mathrm{Th}^{\text {car }} ; \mathrm{NHC}=\mathrm{I}^{\mathrm{MeMe}}, \mathrm{I}^{\mathrm{iPr}}, \mathrm{Ar}=\mathrm{Th}, \mathrm{Th}^{\mathrm{tms}}, \mathrm{Th}^{\mathrm{dpa}} ; \mathrm{NHC}=\mathrm{I}^{\mathrm{PPr}}, \mathrm{Ar}=$ $\mathrm{Th}^{\mathrm{Me} 2}$ ), could only be obtained from saturated solutions left undisturbed for several weeks at room temperature. Their solidstate structures are presented in Fig. 4 (see Supporting Information Fig. S60 for the structure of $\left[\left(1^{\mathrm{MeMe} e}\right) \mathrm{BTh}\right]_{2}$ and Fig. S61 for the connectivity structure of $\left[\left(\left(^{\mathrm{IPr}}\right) B \mathrm{BTh}^{\mathrm{dpa}}\right]_{2}\right)$ and selected bond lengths and angles in Table 3. Unlike their solutions, which were deep purple (or in pink the case of $\left[\left(\mathrm{IIPr}^{\mathrm{Pr}}\right) \mathrm{BTh}^{\mathrm{Me} 2}\right]_{2}$ ), single crystals of these diborenes presented a deep burgundy red color. While the $\mathrm{Th}-, \mathrm{Th}^{\mathrm{tms}}$ - and $\mathrm{Th}^{\mathrm{Me} 2}$-substituted diborenes all crystallized as centrosymmetric molecules, $\mathrm{Th}^{\mathrm{dpa}}$ - and $\mathrm{Th}^{\mathrm{car}}{ }_{-}$ substituted diborenes were slightly unsymmetrical in the solid 
state. The $B-B$ bond lengths range from 1.576(4) $\AA$ in $\left[\left(l^{\mathrm{MeMe}}\right) \mathrm{BTh}\right]_{2}$ to $1.603(4) \AA$ in $\left[\left(\mathrm{I}^{\mathrm{iPr}}\right) \mathrm{BTh}\right]_{2}$ and show no apparent trend depending on the $\mathrm{NHC}$ or thiophene derivative used. These B-B distances are comparable to those found in other $\mathrm{I}^{\mathrm{Me}}$ stabilized 1,2-diaryldiborenes $(1.585(4)-1.593(5) \AA A),{ }^{[8][9]}$ indicating significant $\mathrm{B}=\mathrm{B}$ double bond character. The $\mathrm{B}-\mathrm{C}_{\mathrm{NHC}}$ bonds $(1.582(2)-1.603(3) \AA)$ are considerably shortened compared to the borane precursors $(1.613(3)-1.632(3) \AA$ ), as expected when moving from $\mathrm{sp}^{3}$ - to $\mathrm{sp}^{2}$-hybridized boron. Except in $\left[\left(\left(^{i P r}\right) B T h^{\text {tms }}\right]_{2}\right.$, the NHC ligands are rotated near orthogonally with respect to the central diborene plane (torsion angles: $\left.70.6(2)-89.3(3)^{\circ}\right)$ in order to minimize steric interactions with the thiophene substituents. The $B-C_{T h}$ bonds, all around $1.56 \AA$ in length, are $0.02-0.03 \AA$ shorter than in the borane precursors, which points to some degree of $\pi$-electron delocalization over the 1,2-dithienyldiborene framework. Furthermore, in the Th- and $\mathrm{Th}^{\text {car }}$-substituted diborenes, the thiophene rings lie coplanar with the $\mathrm{B}=\mathrm{B}$ double bond (torsion angle (B1',B1,C10,S1) $\left.0.0(3)-1.8(5)^{\circ}\right)$, even more so than in the $\mathrm{I}^{\mathrm{Me}}$-supported bis(2-furyl)diborene $\left(2.5\right.$ and $\left.5.1^{\circ}\right){ }^{[8]}$ The fact that the $N$-carbazolyl group, though large, is entirely planar and nearly orthogonal to the dithienyldiborene framework (ca. $80^{\circ}$ ), explains its lack of steric influence on the geometry of the molecule and precludes any m-orbital overlap with the planar dithienyldiborene $\pi$-electron framework. This contrasts with the $\mathrm{Th}^{\text {tms }}$-, $\mathrm{Th}^{\mathrm{Me} 2}$ - and $\mathrm{Th}^{\mathrm{dpa}}$-substituted diborenes, in which the thiophene rings deviate significantly from coplanarity with the diborene core. The trimethylsilyl group and the even bulkier diphenylamino substituent in the remote C5-position of the C2bound thiophene ring both cause a relatively small rotation of the thiophene rings $\left(5.1(2)-22.7(2)^{\circ}\right)$, whereas a single vicinal methyl substituent in the C2-position of a C3-bound thiophene increases the torsion angle dramatically to $51.2(3)^{\circ}$, which is comparable to the degree of rotation of the mesityl and duryl ligands in $\left[\left(\left(^{\mathrm{Me}}\right) \mathrm{BMes}\right]_{2}\left(54.1(3)^{\circ}\right)\right.$ and $\left[\left(\mathrm{I}^{\mathrm{Me}}\right) \mathrm{BDur}\right]_{2}\left(55.8(4)^{\circ}\right)$. Overall, regarding the heteroaryl ligands, it seems that sterics play a much more important role than electronics in influencing the degree of coplanarity between the thiophene rings and the diborene core. Variations of the NHC ligands, however, seem to have little effect on the geometry of the molecule. It is noteworthy that the diborenes with a lower degree of coplanarity between thienyl substituents and diborene core also proved much more prone to decomposition in solution, which may be due to the resultant loss of stabilizing $\pi$-conjugation.

Similarly to $\left[\left(\mathrm{l}^{\mathrm{Me}}\right) \mathrm{BTh}\right]_{2}$ and $\left[\left(\mathrm{I}^{\mathrm{Me}}\right) \mathrm{BTh}^{\mathrm{tms}}\right]_{2},{ }^{[8]}$ the UV-vis spectra of $\left[\left(\left(^{\mathrm{MeMe}}\right) \mathrm{BTh}\right]_{2},\left[\left(\mathrm{I}^{\mathrm{PPr}}\right) \mathrm{BTh}\right]_{2},\left[\left(\mathrm{I}^{\mathrm{iPr}}\right) \mathrm{BTh}{ }^{\mathrm{Me} 2}\right]_{2},\left[\left(\mathrm{I}^{\mathrm{PPr}}\right) \mathrm{BTh}{ }^{\mathrm{dpa}}\right]_{2}\right.$ and $\left[\left({ }^{\mathrm{Me}}\right) \mathrm{BTh}^{\mathrm{car}}\right]_{2}$ in $\mathrm{Et}_{2} \mathrm{O}$ all showed three major absorption bands: the first in the $275-330 \mathrm{~nm}$ region, the second in the $483-502 \mathrm{~nm}$ region and the third in the $530-581 \mathrm{~nm}$ region (Fig. 5, Table 4). At such low concentrations the other diborenes decomposed too rapidly to acquire spectra of the pure diborenes. Previous TD-DFT calculations by our group on $\mathrm{I}^{\mathrm{Me}}$-supported diaryldiborenes showed that, independent of the nature of the aryl group, the highest wavelength absorption band always corresponds to the HOMO-LUMO transition, $\pi(\mathrm{B}-\mathrm{B}) \rightarrow \pi(\mathrm{NHC})$, the $483-502 \mathrm{~nm}$ absorption band to the $\pi(\mathrm{B}-\mathrm{B}) \rightarrow \pi(\mathrm{Aryl} / \mathrm{NHC})$ transition and the lowest wavelength absorption band to the $\sigma(\mathrm{B}$ $\mathrm{B}) \rightarrow \pi(\mathrm{NHC})$ transition. ${ }^{[8][9]}$ Based on these calculations, we propose a similar assignment to the three absorption bands of each of the UV-vis spectra presented in Fig. 5, as outlined in Table 4.

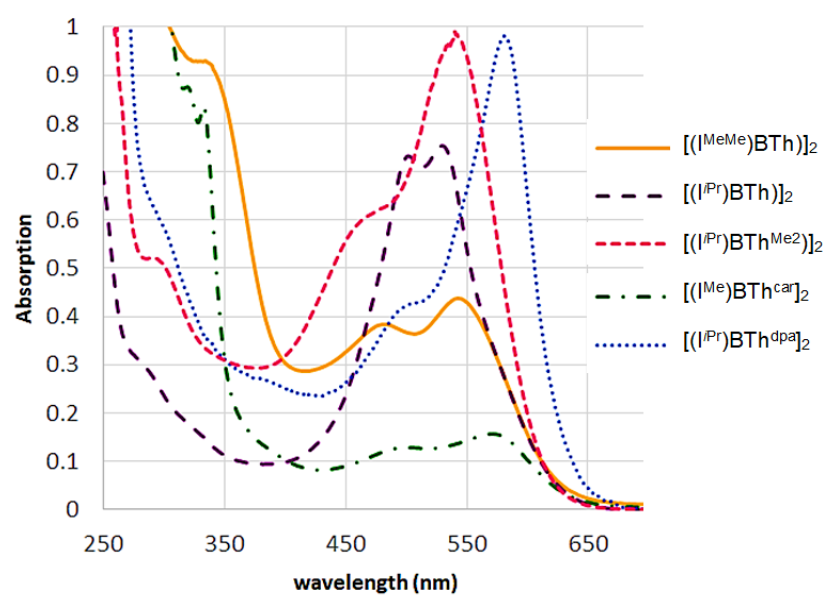

Figure 5. Overlay of UV-vis spectra of $\left.\left[\left(\mathrm{I}^{\mathrm{MeMe}}\right) \mathrm{BTh}\right)\right]_{2}$, $\left[\left(\mathrm{I}^{\mathrm{iPr}}\right) \mathrm{BTh}\right]_{2},\left[\left(\mathrm{I}^{\mathrm{PPr}}\right) \mathrm{BTh}{ }^{\mathrm{Me} 2}\right]_{2}$, $\left[\left(l^{\mathrm{Me}}\right) \mathrm{BTh} h^{\mathrm{car}}\right]_{2}$ and $\left[\left(\mathrm{IPr}^{\mathrm{PP}}\right) \mathrm{BTh}{ }^{\mathrm{dpa}}\right]_{2}$ in $\mathrm{Et}_{2} \mathrm{O}$ at $25^{\circ} \mathrm{C}$.

Table 4. Wavelengths of experimental absorption maxima $(\mathrm{nm})$ for $\mathrm{NHC}$ stabilized bis(thienyl)diborenes in $\mathrm{Et}_{2} \mathrm{O}$ at $25^{\circ} \mathrm{C}$.

\begin{tabular}{|c|c|c|c|}
\hline & $\pi(\mathrm{B}-\mathrm{B}) \rightarrow \pi(\mathrm{NHC})$ & $\pi(\mathrm{B}-\mathrm{B}) \rightarrow \pi(\mathrm{Th} / \mathrm{NHC})$ & $\sigma(\mathrm{B}-\mathrm{B}) \rightarrow \pi(\mathrm{NHC})$ \\
\hline$\left.\left[\left(\mathrm{I}^{\mathrm{Me}}\right) \mathrm{BTh}\right)\right]_{2}^{[8]}$ & 543 & 477 & 293 \\
\hline$\left.\left[\left(1^{\mathrm{MeMe}}\right) \mathrm{BTh}\right)\right]_{2}$ & 543 & 483 & 335 \\
\hline$\left[\left(\mathrm{I}^{\mathrm{IPr}}\right) \mathrm{BTh}\right]_{2}$ & 530 & 502 & 275 \\
\hline$\left[\left(\mathrm{I}^{\mathrm{Me}}\right) \mathrm{BTh}^{\mathrm{tms}}\right]_{2}^{[8]}$ & 562 & 492 & 293 \\
\hline$\left[\left(\mathrm{I}^{\mathrm{IPr}}\right) \mathrm{BTh}{ }^{\mathrm{Me} 2}\right]_{2}$ & 540 & 483 & 291 \\
\hline$\left[\left(\mathrm{l}^{\mathrm{Me}}\right) \mathrm{BTh}^{\mathrm{car}}\right]_{2}$ & 572 & 499 & 330 \\
\hline$\left[\left(\mathrm{I}^{\mathrm{IPr}}\right) \mathrm{BTh}{ }^{\mathrm{dpa}}\right]_{2}$ & 581 & 499 & 303 \\
\hline
\end{tabular}

Comparison of the relative positions of the three absorption maxima provides a qualitative comparison of the electronic influences of the various NHC and thienyl groups employed in this study. The highest wavelength absorption maximum of the $[(\mathrm{NHC}) \mathrm{BTh}]_{2}$ derivatives $\left(\mathrm{NHC}=\mathrm{I}^{\mathrm{Me}}, \mathrm{I}^{\mathrm{MeMe}}, \mathrm{I}^{\mathrm{iPr}}\right)$ undergoes a small blue-shift when switching from $\mathrm{I}^{\mathrm{Me}} / \mathrm{I}^{\mathrm{MeMe}}(543 \mathrm{~nm})$ to $\mathrm{I}^{\mathrm{IPr}}$ $(530 \mathrm{~nm})$, which corresponds to a slight increase of the $\pi(B-$ $B) \rightarrow \pi(\mathrm{NHC})$ gap. This can be explained by the increased $\pi-$ acceptor properties of the NHC ligands when moving from $\mathrm{I}^{\mathrm{Me}} / \mathrm{I}^{\mathrm{MeMe}}$ to $\mathrm{I}^{\mathrm{iPr}}$ (see Table 1), which results in the stabilization of the HOMO (the B-B $\pi$ bond), through $\pi$-backdonation to the carbenes. The $\left[\left(I^{\mathrm{PP}}\right) \mathrm{BTTh}{ }^{\mathrm{Me} 2}\right]_{2}$ derivative, despite displaying the largest angle between the thiophene and diborene planes (ca. $\left.50^{\circ}\right)$, shows overall similar transition energies to $\left.\left[\left(\mathrm{I}^{\mathrm{Me}}\right) \mathrm{BTh}\right)\right]_{2}$, suggesting that the coplanarity of the thiophene rings with the diborene core has little influence upon the relative energies of the frontier orbitals.

In contrast, the nature of the $\mathrm{C} 3$ susbtituent of the 2-thienyl ligands seems to have a much more pronounced effect. The presence of sterically demanding and electron-donating trimethylsilyl, $\mathrm{N}$-carbazolyl or diphenylamino C3 substituents causes a significant red-shift in the HOMO $\rightarrow$ LUMO absorption, from $\left[\left(\mathrm{I}^{\mathrm{Me}}\right) \mathrm{BTh} \mathrm{h}^{\mathrm{tms}}\right]_{2}(562 \mathrm{~nm})^{[8]}$ to $\left[\left(\mathrm{I}^{\mathrm{Me}}\right) \mathrm{BTh}^{\mathrm{car}}\right]_{2}(572 \mathrm{~nm})$ to $\left[\left(\mathrm{IPr}^{\mathrm{Pr}}\right) \mathrm{BTh}^{\mathrm{dpa}}\right]_{2}(581 \mathrm{~nm}) .^{[31]}$ Since DFT calculations show that the LUMO does not extend significantly over the thiophene rings, ${ }^{[8]}$ this decrease in the HOMO-LUMO gap must result from the destabilization of the HOMO, as was hoped for when introducing these electron-donating groups. 


\section{Conclusions}

This study has shown that even small changes in the substitution pattern and electronics of both the stabilizing $\mathrm{NHC}$ ligands and the anionic substituents have perceptible effects on the geometry and electronic stability of diborenes.

UV-vis spectroscopic data showed that even a small increase in the $\pi$-acceptor properties of the $\mathrm{NHC}$ ligands stabilizes the HOMO of the diborene, presumably through increased $\pi$-backdonation. Furthermore, while (dihalo)thienyldiboranes bearing relatively small NHCs, such as $\mathrm{I}^{\mathrm{Me}}, \mathrm{I}^{\mathrm{MeMe}}$ or $\mathrm{I}^{\mathrm{PPr}}$, are readily reduced to diborenes, this becomes impossible with the more sterically demanding $\mathrm{I}^{\text {Mes }}$ ligand, as excessive steric hindrance around the boron center prevents dimerization of the intermediate borylene, thus favoring $\mathrm{C}-\mathrm{H}$ activation reactions.

While substitution of 2-thienyl ligands in the remote C3position with sterically demanding trimethylsilyl or diphenylamino groups resulted in significant rotation $\left(5-23^{\circ}\right)$ of the thiophene rings out of the diborene plane, this was particularly exacerbated when using vicinally substituted 2,5-dimethyl-3-thienyl ligands, which rotated by ca. $50^{\circ}$ out of the diborene plane to release steric strain.

At first sight, structural analysis of dithienyldiborenes bearing electron-donating diarylamino substituents suggested no orbital overlap between the lone pair on the nitrogen and the $\pi$ system of the thiophene rings and, thereby, the B-B m-bonding orbital. However, UV-vis spectra of these species revealed a small but significant decrease in the HOMO-LUMO gap compared to the unsubstituted analogues, which can be related to an increase in the energy of the HOMO.

Unfortunately, these new, more electron-rich diborenes proved too unstable to allow any reactivity studies: the smaller their HOMO-LUMO gap, the faster they decomposed at room temperature in solution and under inert atmosphere, making even their isolation challenging. It thus seems that the simple $\mathrm{I}^{\mathrm{Me}}$-supported 1,2-bis(2-thienyl)diborene, with its rather limited reactivity scope, still remains both the easiest to synthesize and the "best behaved" of the reactive $\left[(\mathrm{NHC}) \mathrm{BTh}^{\mathrm{R}}\right]_{2}$ derivatives.

\section{Experimental Section}

Electronic Supplementary Information (ESI) available: synthesis and characterization of new compounds, NMR spectra, crystallographic details and supplementary structures. Cif files of crystallographic structures have been deposited with the Cambridge Crystallographic Data Centre: CCDC 1577253-1577268. See DOI: xxx

\section{Acknowledgements}

This project was funded by the European Research Council (ERC) under the European Union Horizon 2020 Research and Innovation Program (grant agreement no. 669054). Financial support from the Alexander von Humboldt Foundation (postdoctoral fellowship for M.A.) is gratefully acknowledged. Many thanks also go to Dr Marc-André Légaré for insightful discussions on the electronics of these diborenes. The authors thank AllyChem Ltd. for a generous gift of $\mathrm{B}_{2}\left(\mathrm{NMe}_{2}\right)_{4}$.
Keywords: Diborenes • N-heterocyclic carbenes • Electron donors • Structural analysis • Spectroscopy

[1] M. Arrowsmith, H. Braunschweig, T. E. Stennett, Angew. Chem. Int. Ed. 2017, 56, 96-115.

[2] a) L. B. Knight, K. Kerr, P. K. Miller, C. A. Arrington, J. Phys. Chem. 1995, 99, 16842-16848; b) T. J. Tague, L. Andrews, J. Am. Chem. Soc. 1994, 116, 4970-4976; c) M. Peric, B. Ostojic, B. Engels, J. Mol. Spectrosc. 1997, 182, 280-294; d) M. Peric, B. Ostojic, B. Engels, J. Mol. Spectrosc.1997, 182, 295-308.

[3] a) Y. Wang, B. Quillian, P. Wei, C. S. Wannere, Y. Xie, R. B. King, H. F. Schaefer III, P. v. R. Schleyer, G. H. Robinson, J. Am. Chem. Soc. 2007, 129, 12412 -12413; b) Y. Wang, B. Quillian, P. Wei, Y. Xie, C. S. Wannere, R. B. King, H. F. Schaefer III, P. v. R. Schleyer, G. H. Robinson, J. Am. Chem. Soc. 2008, 130, 3298-3299.

[4] H. Braunschweig, A. Damme, R. D. Dewhurst, A. Vargas, Nat. Chem. 2013, 5, 115-121.N. Arnold, H. Braunschweig, R. D. Dewhurst, W. C. Ewing, J. Am. Chem. Soc. 2016, 138, 76-79.

[5] H. Braunschweig, R. D. Dewhurst, K. Hammond, J. Mies, K. Radacki, A. Vargas, Science 2012, 336, 1420-1422.

[6] M. Arrowsmith, J. Böhnke, H. Braunschweig, M. A. Celik, T. Dellermann, K. Hammond, Chem. Eur. J. 2016, 22, 17169-17172

[7] J. Böhnke, H. Braunschweig, T. Dellermann, W. C. Ewing, T. Kramer, I. Krummenacher, A. Vargas, Angew. Chem. Int. Ed. 2015, 54, 44694473.

[8] H. Braunschweig, R. D. Dewhurst, C. Hörl, A. K. Phukan, F. Pinzner, S. Ullich, Angew. Chem. Int. Ed. 2014, 53, 3241-3244.

[9] P. Bissinger, H. Braunschweig, A. Damme, T. Kupfer, A. Vargas, Angew. Chem. Int. Ed. 2012, 51, 9931-9934.

[10] P. Bissinger, H. Braunschweig, A. Damme, C. Hörl, I. Krummenacher, T. Kupfer, Angew. Chem. Int. Ed. 2015, 54, 359-362

[11] P. Bissinger, H. Braunschweig, A. Damme, T. Kupfer, I. Krummenacher, A. Vargas, Angew. Chem. Int. Ed. 2014, 53, 5689-5693.

[12] P. Bissinger, H. Braunschweig, M. A. Celik, C. Claes, R. D. Dewhurst, S. Endres, H. Kelch, T. Kramer, I. Krummenacher, C. Schneider, Chem. Commun. 2015, 51, 15917-15920.

[13] S. R. Wang, M. Arrowsmith, J. Böhnke, H. Braunschweig, T. Dellermann, R. D. Dewhurst, H. Kelch, I. Krummenacher, J. D. Mattock, J. H. Müssig, T. Thiess, A. Vargas, J. Zhang, Angew. Chem. Int. Ed. 2017, 56, 8009-8013

[14] W. Lu, Y. Li, R. Ganguly, R. Kinjo, J. Am. Chem. Soc. 2017, 139, 5047-5050.

[15] W. Lu, Y. Li, R. Ganguly, R. Kinjo, Angew. Chem. Int. Ed. 2017, 56, $9829-9832$

[16] a) S. R. Wang, M. Arrowsmith, H. Braunschweig, R. D. Dewhurst, M. Dömling, J. D. Mattock, C. Pranckevicius, A. Vargas, J. Am. Chem. Soc. 2017, 139, 10661-10664; b) P. Bissinger, A. Steffen, A. Vargas, R. D. Dewhurst, A. Damme, H. Braunschweig, Angew. Chem. Int. Ed. 2015, 54, 4362-4366.

[17] H. Braunschweig C. Hörl, Chem. Commun., 2014, 50, 10983-10985.

[18] M. Arrowsmith, J. Böhnke, H. Braunschweig, M. A. Celik, C. Claes, W. C. Ewing, I. Krummenacher, K. Lubitz, C. Schneider, Angew. Chem. Int. Ed. 2016, 55, 11271-11275

[19] H. Braunschweig, T. Dellermann, W. C. Ewing, T. Kramer, C. Schneider, S. Ullrich, Angew. Chem. Int. Ed. 2015, 54, 10271-10275

[20] H. Braunschweig, P. Constantinidis, T. Dellermann, W. C. Ewing, I. Fischer, M. Hess, F. R. Knight, A. Rempel, C. Schneider, S. Ullrich, A. Vargas, J. D. Woollins, Angew. Chem. Int. Ed. 2016, 55, 5606-5609

[21] C. A. Tolman, Chem. Rev. 1977, 77, 313-348.

[22] O. Back, M. Henry-Ellinger, C. D. Martin, D. Martin, G. Bertrand, Angew. Chem. Int. Ed. 2013, 52, 2939-2943.

[23] A. C. Hillier, W. J. Sommer, B. S. Yong, J. L. Petersen, L. Cavallo, S. P. Nolan, Organometallics 2003, 22, 4322-4326.

[24] A. Gómez-Suárez, D. J. Nelson, S. P. Nolan, Chem. Commun. 2017, $53,2650-2660$

[25] D. G. Gusev, Organometallics 2009, 28, 6458-6461.

[26] T. Krachko, M. Bispinghoff, A. M. Tondreau, D. Stein, M. Baker, A. W. Ehlers, J. C. Slootweg, H. Grützmacher, Angew. Chem. Int. Ed. 2017, 56, 7948-7951. 
[27] a) A. Sundararaman, R. Varughese, H. Li, L. N. Zakharov, A. L. Rheingold, F. Jäkle, Organometallics 2007, 26, 6126-6131; b) K. Parab K. Venkatasubbaiah, F. Jäkle, J. Am. Chem Soc. 2006, 128, 1287912885.

[28] a) L. Weber, J. Halama, L. Böhling, A. Brockhinke, A. Chrostowska, C. Darrigan, A. Dargelos, H.-G. Stammler, B. Neumann, Eur. J. Inorg Chem. 2013, 4268-4279; b) L. Weber, J. Halama, L. Böhling, A Chrostowska, A. Dargelos, H.-G. Stammler, B. Neumann, Eur. J. Inorg. Chem. 2011, 3091-3101; c) L. Weber, J. Halama, V. Werner, K. Hanke, L. Böhling, , A. Chrostowska, A. Dargelos, M. Maciejczyk, A.-L. Raza, H.-G. Stammler, B. Neumann, Eur. J. Inorg. Chem. 2010, 5416-5425

[29] a) Arrowsmith, J. Böhnke, H. Braunschweig, H. Gao, M.-A. Légaré, V. Paprocki, J. Seufert, Chem. Eur. J. 2017, 23, 12210-12217; b) M. N. Arnold, H. Braunschweig, R. D. Dewhurst, F. Hupp, K. Radacki, A. Trumpp, Chem. Eur. J. 2016, 22, 13927-13934; c) D. P. Curran, A Boussonnière, S. J. Geib, E. Lacôte, Angew. Chem. Int. Ed. 2012, 51, 1602-1605; d) P. Bissinger, H. Braunschweig, A. Damme, R. D. Dewhurst, T. Kupfer, K. Radacki, K. Wagner, J. Am. Chem. Soc. 2011, 133, 19044-19047; e) Y. Wang, G. H. Robinson, Inorg. Chem. 2011 50, 12326-12337.

[30] H. Braunschweig, I. Krummenacher, M.-A. Légaré, A. Matler, K. Radacki, Q. Ye, J. Am. Chem. Soc. 2017, 139, 1802-1805.

[31] Since a $13 \mathrm{~nm}$ blue-shift in the HOMO $\rightarrow$ LUMO transition is observed when switching from $\mathrm{I}^{\mathrm{Me}}$ to $\mathrm{I}^{\mathrm{iPr}}$ in $[(\mathrm{NHC}) \mathrm{BTh}]_{2}$, it can be assumed that $\left[\left(\mathrm{I}^{\mathrm{Me}}\right) \mathrm{BTh}{ }^{\mathrm{dpa}}\right]_{2}$ presents an even smaller HOMO-LUMO gap than $\left[\left(\mathrm{I}^{\mathrm{iPr}}\right) \mathrm{BTh}^{\mathrm{dpa}}\right]_{2}$. 


\section{Entry for the Table of Contents}

Mind the gap: In order to increase the reactivity of the $\mathrm{B}=\mathrm{B}$ double bond, electron-donating groups were installed on the heteroaryl rings of NHC-supported 1,2-

dithienyldiborenes. While the coplanarity of the thiophenes and the diborene core proved highly dependent on sterics, any increase in the electron-donating ability of the substituents resulted in the destabilization of the HOMO and greater instability of the resulting diborenes.
LUMO

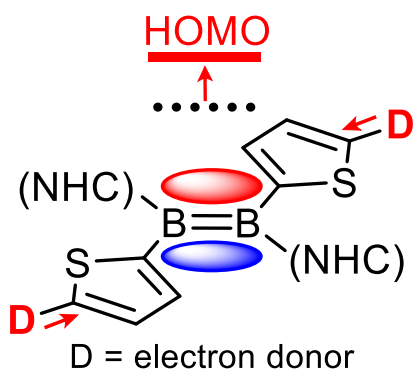

D. Auerhammer, M. Arrowsmith, $P$. Bissinger, $H$. Braunschweig, ${ }^{*} T$. Dellermann, T. Kupfer, C. Lenczyk, D. K. Roy, M. Schäfer, C. Schneider

Page No. - Page No.

Increasing the Reactivity of Diborenes: Derivatization of NHCSupported Dithienyldiborenes with Electron-Donor Groups 